\title{
A 10W LOW COST OFDM TRANSCEIVER (LCOT)
}

\author{
Pallavi Sandhiya, Nazrul Zaki, Rickey Satterfield, Steve Bundick, Keith \\ Thompson and Charles Grant \\ NASA/GSFC Wallops Flight Facility, Wallops Island, VA
}

\begin{abstract}
1.0 ABSTRACT
This paper details design, development and test of the Low Cost OFDM Transceiver (LCOT) LCT2-040-2200 module at S band. The goal of the project is to provide a low cost transmit and receive unit for demonstrating OFDM communication on a flight platform. The LCOT module is built to transmit and receive OFDM signals. It transmits OFDM signals at $10 \mathrm{~W}$ power out through a custom built high power amplifier and conforms to the IEEE 802.11.g spectral emissions mask.
\end{abstract}

Key Words: Transceiver, OFDM, power amplifier, $\mathrm{S}$ band

\subsection{INTRODUCTION}

Increasing demand for higher data throughput coupled with limitations on available spectrum has motivated several efforts focused on the development of new higher efficiency waveforms for use in the challenging aeronautical telemetry environment where there is a strong need for greater channel capacity

The OFDM waveform uses space, frequency and time diversity, as well as innovative signal processing techniques to achieve five times the spectral efficiency of legacy PCM/FM while maintaining a similar detection efficiency. The technical challenge involves the generation of complex LDPC codes, generation of OFDM modulation signal, and generation of a $10 \mathrm{~W}$ high PAPR amplifier inside a small and ruggedized enclosure.

The Low Cost OFDM Transceiver (LCOT) is based on NASA's legacy LCT2 platform and solves this technical challenge by using state of the art COTS RF devices for the analog front and back ends, and by incorporating Field Programmable Gate Arrays (FPGA) as its main digital signal processing engine.

Figure 2.0 shows the implementation of the LCOT system in flight configuration. 


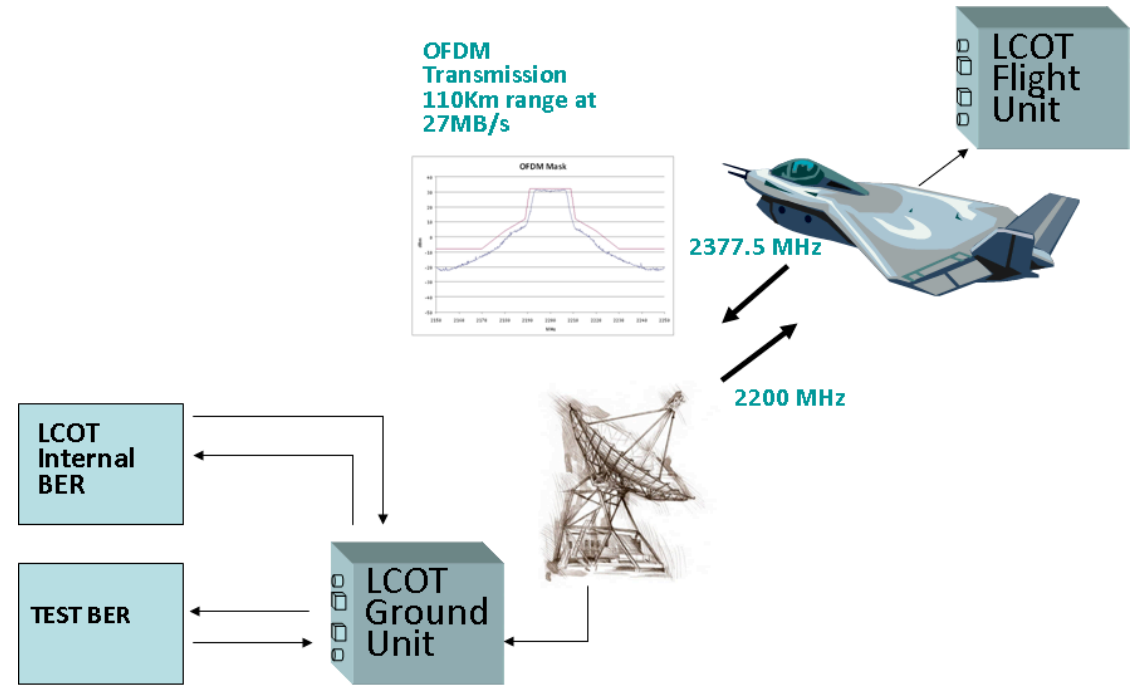

Figure 2.0: LCOT system flight

\subsection{LCOT SYSTEM SPECIFICATIONS}

This section details the specifications of the LCOT system and its main components. The section begins with a table of specifications as well as a description of the required spectral emissions mask.

\subsection{TRANSCEIVER REQUIREMENTS}

The specifications of the LCOT module determine the required performance of the transceiver in order to comply with the link budget. An abbreviated specification table is given in Table 3.1.

\subsection{OFDM TRANSMIT SPECTRAL MASK}

The LCOT module was required to transmit $10 \mathrm{~W}$ and to conform to the IEEE 802.11.g transmit spectral mask. The specifications are shown in Figure 3.0 below. IEEE defines the permitted distribution of signal power for each 802.11 layer amendment and to which the measured Spectral Mask must be compared:

When transmitting in a $20 \mathrm{MHz}$ channel, the transmitted spectrum must have a $0 \mathrm{dBr}$ bandwidth not exceeding $18 \mathrm{MHz},-20 \mathrm{dBr}$ at $11 \mathrm{MHz}$ frequency offset, $-28 \mathrm{dBr}$ at $20 \mathrm{MHz}$ frequency offset, and the maximum of $-45 \mathrm{dBr}$ and $-53 \mathrm{dBm} / \mathrm{MHz}$ at $30 \mathrm{MHz}$ frequency offset and above. The transmitted distribution of power of the transmitted signal must fall within the Spectral Mask shown in Figure 3.0. 


\begin{tabular}{|c|c|c|c|}
\hline & Parameter & Range & Notes \\
\hline 1.0 & Transmitter & & \\
\hline 1.1 & RF Power Output & $10 \mathrm{~W}$ min. & Matched load assumed \\
\hline 1.2 & Output Impedance & $50 \Omega$ & \\
\hline 1.3 & Load VSWR & $<2: 1$ & \\
\hline 1.4 & Frequency Range & $2200 \mathrm{MHz}$ & \\
\hline 1.5 & Spurious Outputs & $\begin{array}{l}>-20 \mathrm{dBr} \text { (at } 11 \% \text { of } \mathrm{Fc} \text { ) } \\
>-28 \mathrm{dBr} \text { (at } 20 \% \text { of } \mathrm{Fc} \text { ) } \\
>-40 \mathrm{dBr} \text { (within } 50 \mathrm{MHz} \text { of } \mathrm{Fc} \text { ) }\end{array}$ & Specified at $2.2 \mathrm{GHz}$ \\
\hline 1.6 & Spectral Mask & OFDM & \\
\hline 2.0 & Modulation Performance & & \\
\hline 2.1 & Modulation Modes & $\begin{array}{llll}\text { QPSK } & \text { OFDM } & \text { or } & 16-Q A M \\
\text { OFDM } & & & \end{array}$ & User programmable \\
\hline 2.2 & Data Rates & $\begin{array}{l}<15 \text { Mbps QPSK } \\
<28 \text { Mbps 16-QAM }\end{array}$ & \\
\hline 2.3 & Carrier Suppression & $>30 \mathrm{~dB}$ & \\
\hline 2.5 & Forward error correction & LDPC Rate $1 / 2,2 / 3,3 / 4$ or $4 / 5$ & $\begin{array}{l}\text { Code rate programmable via } \\
\text { user control/status interface }\end{array}$ \\
\hline 3.0 & Receiver & & \\
\hline 3.1 & Center Frequency & $2377.5 \mathrm{MHz}$ & \\
\hline 3.2 & Input Impedance & $50 \Omega$ & \\
\hline 3.3 & Noise Figure & $<2.5 \mathrm{~dB}$ & \\
\hline 3.7 & Modulation & OFDM ( QPSK or 16-QAM ) & \\
\hline 3.8 & Data rate & $\begin{array}{l}<15 \text { Mbps QPSK } \\
<28 \text { Mbps 16-QAM }\end{array}$ & \\
\hline 4.0 & Power Interface & & \\
\hline 4.1 & Input Voltage & $28 \mathrm{VDC}$ & \\
\hline 4.2 & Power & $\begin{array}{l}112 \mathrm{~W}, 4 \mathrm{~A} \text { (Rx mode only) } \\
154 \mathrm{~W}, 5.5 \mathrm{~A}(\mathrm{Tx} \& \mathrm{Rx})\end{array}$ & \\
\hline 4.3 & Idle Current & $4 \mathrm{~A}$ & 7.0 A Current limit for in-rush \\
\hline 5.0 & User interfaces & & \\
\hline 5.1 & RS232 control/status & & Serial Asynchronous UART \\
\hline 5.2 & $\begin{array}{l}\text { LVDS Serial Data Output } \\
\text { Interface }\end{array}$ & $\begin{array}{l}\mathrm{V}_{\mathrm{CM}}: 1.2 \mathrm{~V} \\
\text { Diff Output Voltage Magnitude: } \\
247 \mathrm{mV} / 454 \mathrm{mV} \mathrm{min} / \mathrm{max} \text { into } \\
100 \Omega \text { differential load. }\end{array}$ & Differential Data and clock \\
\hline 5.3 & $\begin{array}{l}\text { LVDS Serial Data Input } \\
\text { Interface }\end{array}$ & $\begin{array}{l}\mathrm{V}_{\mathrm{CM}}: 1.2 \mathrm{~V} \\
\text { Diff Input Threshold: } 100 \mathrm{mV} \\
\text { min. } \quad \text { Diff Termination: } \\
100 \Omega\end{array}$ & Differential Data and clock \\
\hline 5.4 & $\begin{array}{lll}\text { Ethernet } & \text { UDP/IP } & \text { Data } \\
\text { Interface }\end{array}$ & 10/100Base-T & \\
\hline 6.0 & Mechanical & & \\
\hline 6.1 & Size & 5.5 "x 5" x2.25" & \\
\hline 6.2 & Weight & 3 lbs (approx) & \\
\hline
\end{tabular}

Table 3.1: LCOT Module Specifications 


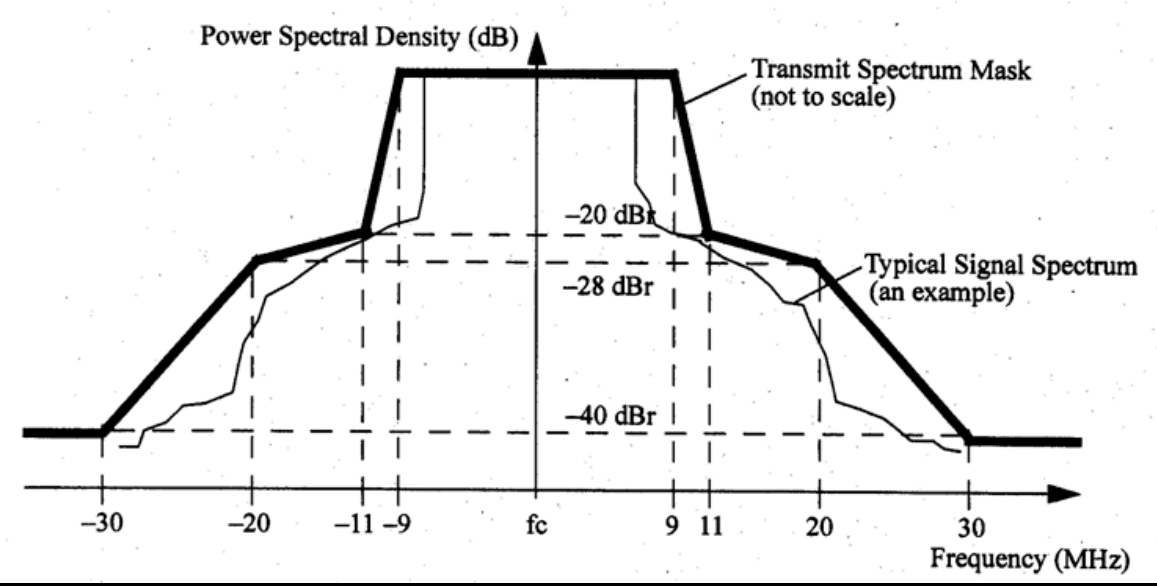

Figure 3.0: IEEE 802.11g Transmit Spectral mask for 20 MHz channel.

\subsection{LCOT SYSTEM DESCRIPTION}

The dynamic range of the LCOT system is $36 \mathrm{~dB}$ when tested in the lab using loop back mode. In this mode, the output of the LCOT at $10 \mathrm{~W}, 2200 \mathrm{MHz}$ is attenuated and down-converted through a series of mixers to translate the signal to the LCOT receiver frequency at $2377.5 \mathrm{MHz}$. The slant range is $110 \mathrm{~km}$ and is recorded at the point where the receiver ceases to be error free under these conditions.

\subsection{DESIGN APPROACH}

The LCOT module consists of the mezzanine section, transceiver, HPA module and DC/DC converter board. The interfaces between the various sections are shown in the system diagram in Figure 4.2 below. The main inputs are the RF input, the DC power input, the Ethernet, the RS232 control and the LVDS I/O. The main outputs are the RF output from the HPA and the LVDS outputs.

\subsection{SUBSYSTEMS}

In this section, the individual subsystems for the LCOT module are described in detail.

\section{DC/DC CONVERTER:}

The LCOT is powered off two Vicor Converters. The PA DC converter is V24C28T100BL2. The $5 \mathrm{~V}$ converter is V24C5H100BG2. These are shown in Figure 4.3 below. Voltage regulators are used on each subsidiary power line to supply individual voltages to the mezzanine, transceiver and HPA boards. The input power to the LCOT is $28 \mathrm{~V}$ and $6 \mathrm{~A}$. 


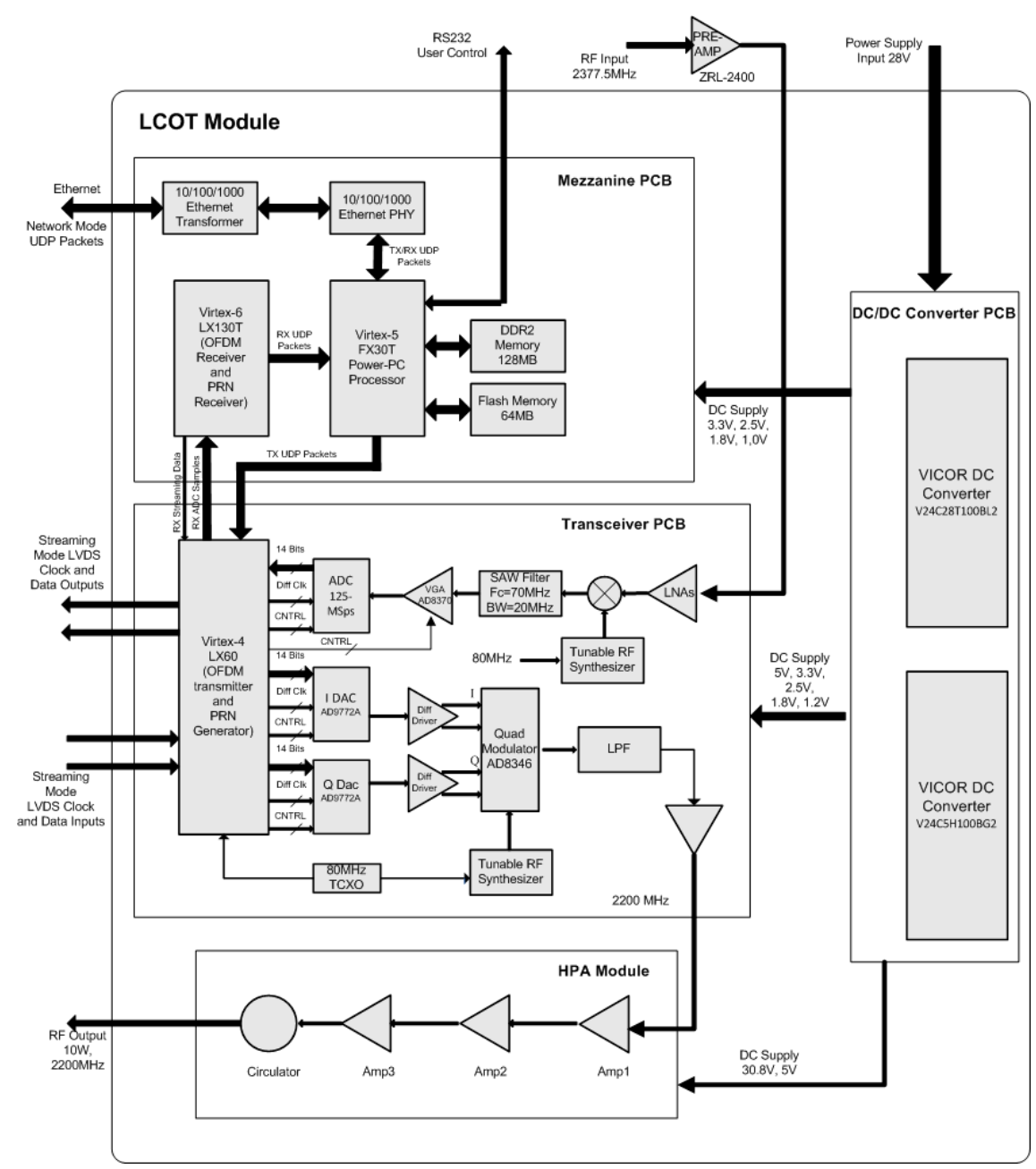

Figure 4.2: System diagram for the LCOT module.

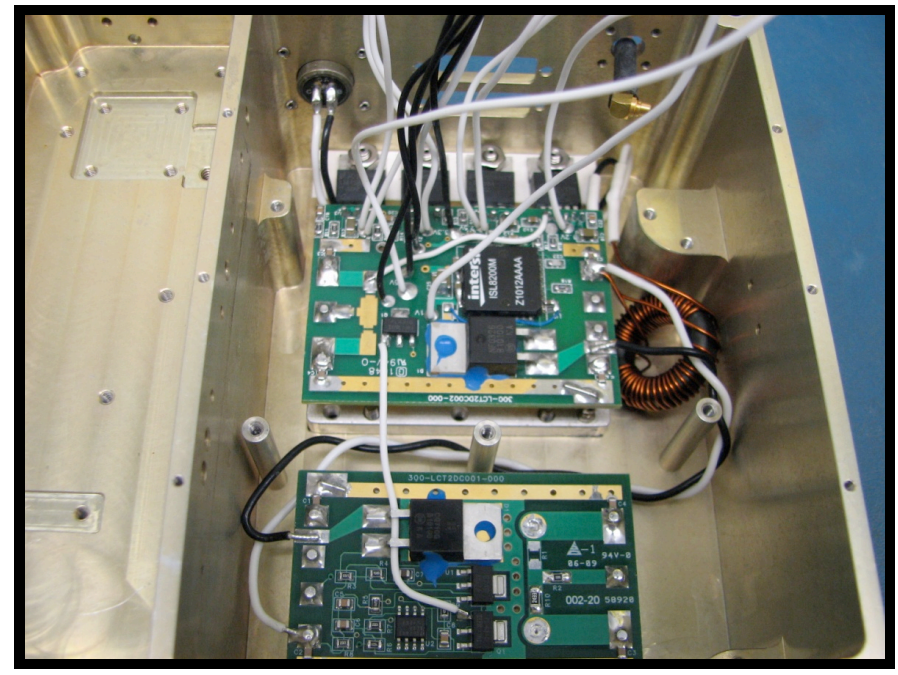

Figure 4.3: Photograph of the DC/DC converters for the LCOT module. 
The transceiver board is shown in Figure 4.4 below. The transmitter receives user data from the LVDS serial clock and data (streaming mode), the network UDP (network mode), or from the internal PRN generator (streaming mode). The Virtex-4 FPGA performs LDPC encoding and OFDM modulation of the received user data. The real (I) and imaginary (Q) components of the OFDM signal are converted into analog domain using two AD9772A DACs. The AD8346 modulator generates an S-Band $(2200 \mathrm{MHz})$ OFDM signal from the two I and Q analog signals. The S-Band signal is amplified to a medium power level $(0-4 \mathrm{dBm})$ for input to the high power amplifier module.

On the receive side, the RF receive frequency is set to $2377.5 \mathrm{MHz}$. This $\mathrm{RF}$ signal is fed through a pre-amp, ZRL-2400, and then through two stages of low noise -amplification. The HLX synthesizer mixes with the input RF frequency to down-convert to $70 \mathrm{MHz}$. The AD8370 variable gain amplifier is part of the receiver AGC. Its gain is adjusted during OFDM short preamble period and then held constant for the remaining of the OFDM packet. The resulting down-converted signal is fed through to the ADC. The ADC feeds the digitized signal to the Virtex-4 FPGA and on to the Virtex-6 FPGA on the mezzanine for OFDM demodulation.

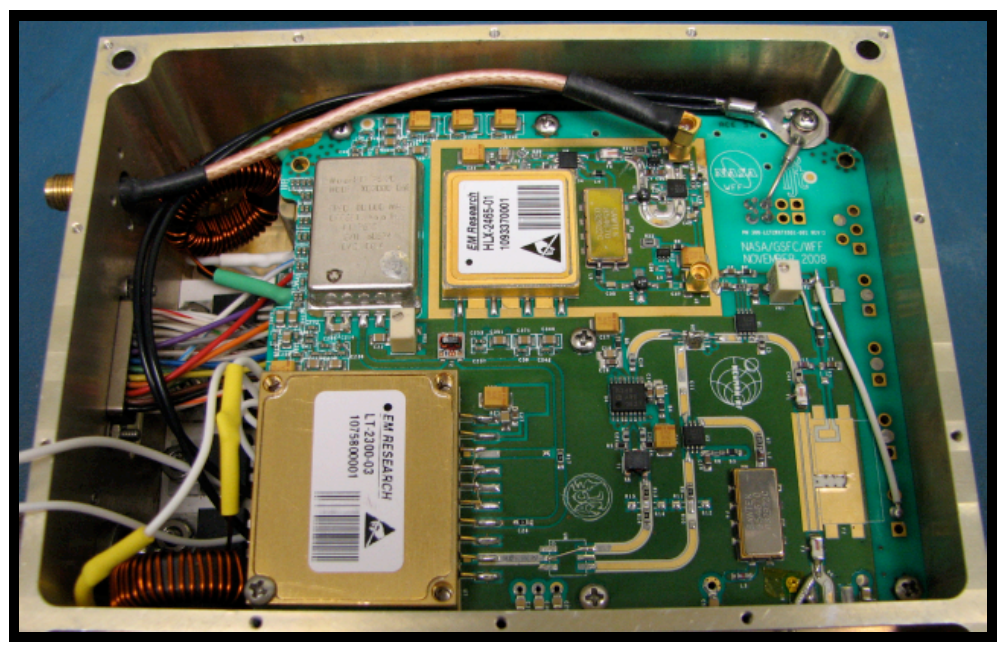

Figure 4.4: Photograph of the Transceiver board (RF side).

\section{MEZZANine BOARD :}

The mezzanine board consists of Virtex-5 and Virtex-6 FPGAs. The Virtex-6 FPGA receives the digitized OFDM signal from the Virtex-4 FPGA on the transceiver board. The Virtex-6 FPGA performs demodulation and LDPC decoding of the OFDM signal. The recovered UDP packets are fed to the Virtex-5 FPGA for network output, whilst the recovered streaming data is fed to the Virtex-4 FPGA for LVDS serial clock and data output. The streaming data is also fed to the internal PRN receiver for BER calculation. 
The Virtex-5 FPGA includes an embedded Power-PC processor that performs networking (TCP/UDP/IP) stack for LCOT. The processor also provides the user control interface through the UART port. The processor system diagram is shown in Figure 4.5 below. The processor clock speed is $400 \mathrm{MHz}$ whilst the system bus speed is $100 \mathrm{MHz}$.

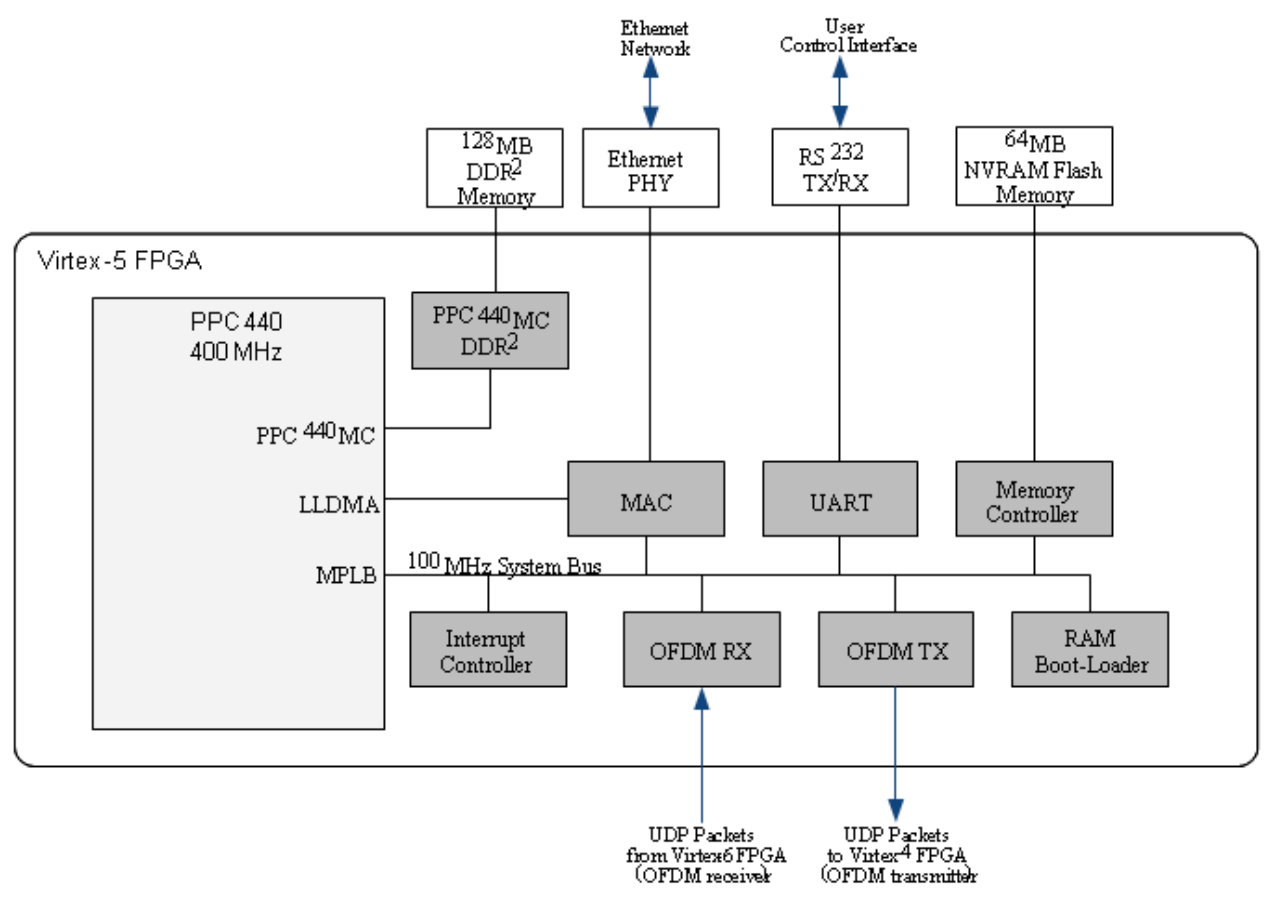

Figure 4.5: PowerPC 440 System Block Diagram

\section{POWER AMPLifier :}

The devices used in the LCT2-040-2200 power amplifier module were GaN devices manufactured by Nitronex. These were seen to be the optimum choice in terms of available output power, bandwidth and efficiency. Three devices were used, NPTB00004, NPTB00050 and NPT25100, to form a three stage high power amplifier.

The three stage LCOT power amplifier was simulated on ADS. The S parameters and nonlinear models for the transistor devices were obtained from Nitronex. The first stage was designed for maximum gain and good input return loss. The second stage was designed for flat gain. The third stage was designed for maximum power delivered to the load. All stages were designed to be unconditionally stable.

The dimensions of the LCOT PA are $3.74 \times 1.24$ inches. The layout is shown below in Figure 4.6 along with a description of the various sections of the module. 


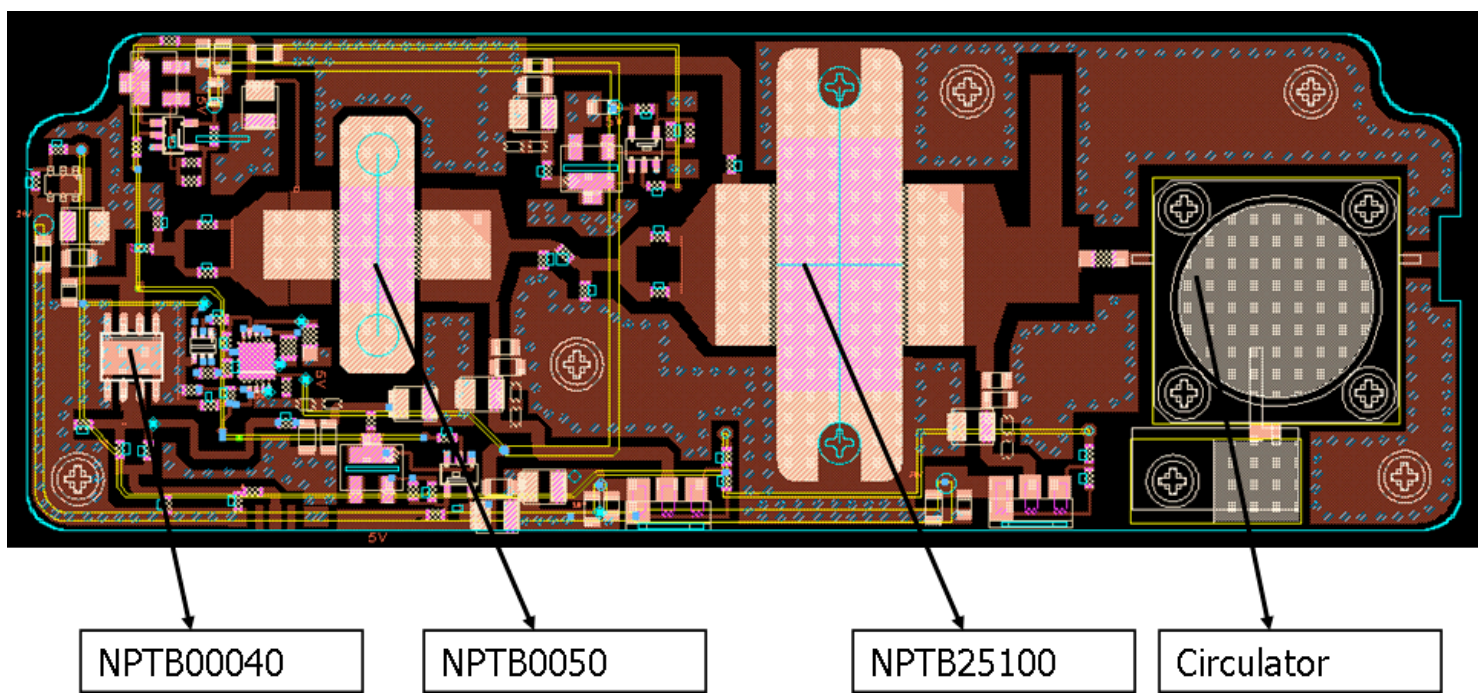

Figure 4.6: The four main components are shown: NPTB00004, NPTB00050, NPT25100 and the CAD215 circulator.

\subsection{TEST RESULTS}

Measurements of the LCOT were taken in the lab at Edwards Air Force Base. A test transceiver was used to generate a two way link to test successful and error free demodulation of the received OFDM signal. In addition, the transmitted signal at $10 \mathrm{~W}$ average output power met the IEEE $802.11 \mathrm{~g}$ transmit spectral mask and data was received with no errors over the full dynamic range.

Figure 5.1 shows a photograph of the LCOT module during testing. The small ruggedized enclosure is suitable for mounting on a flight platform. Figure 5.2 shows a plot of the OFDM transmitted signal captured on a spectrum analyzer at $10 \mathrm{~W}$ average output power. 


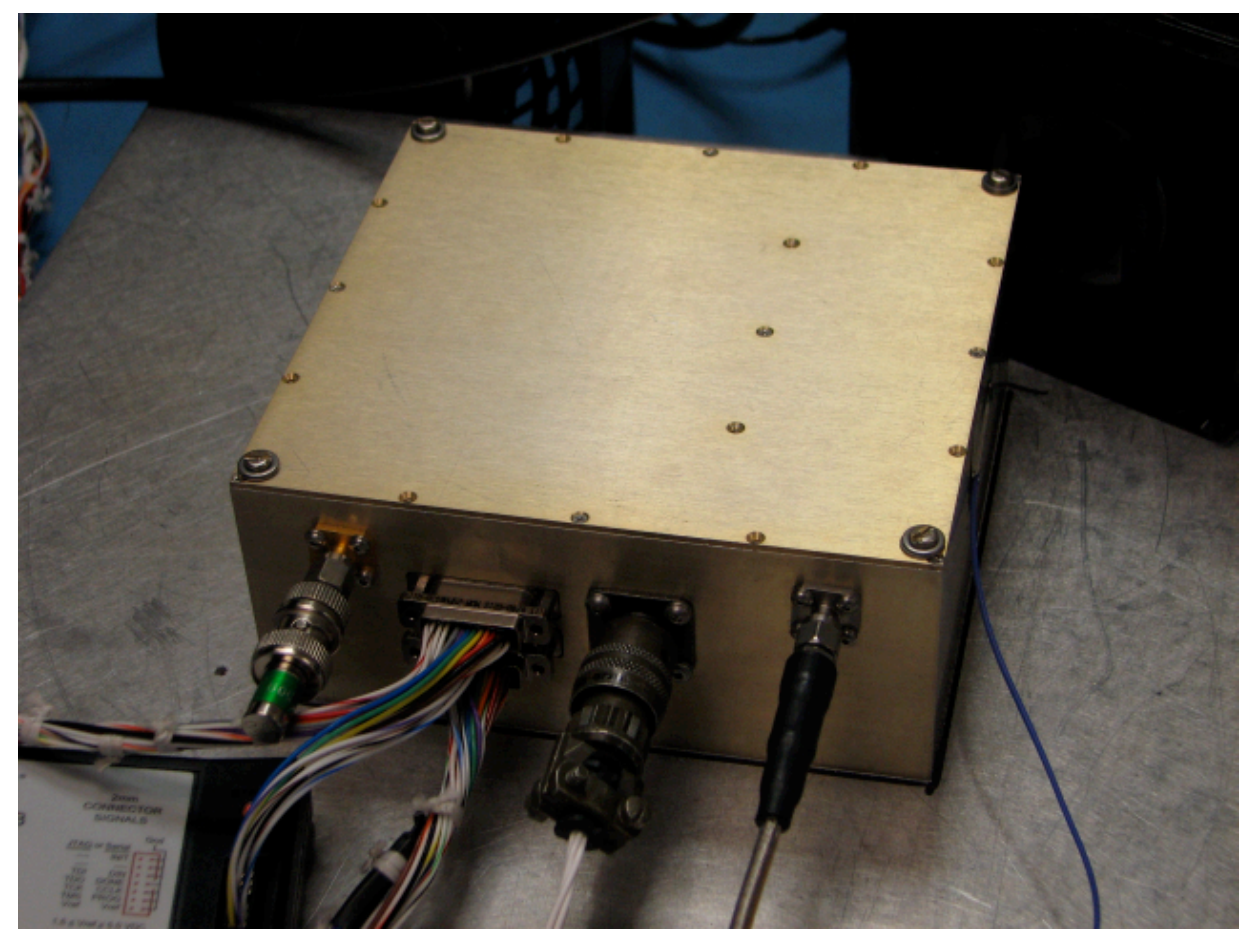

Figure 5.1: Photograph of the LCOT module (pre-amp not shown).

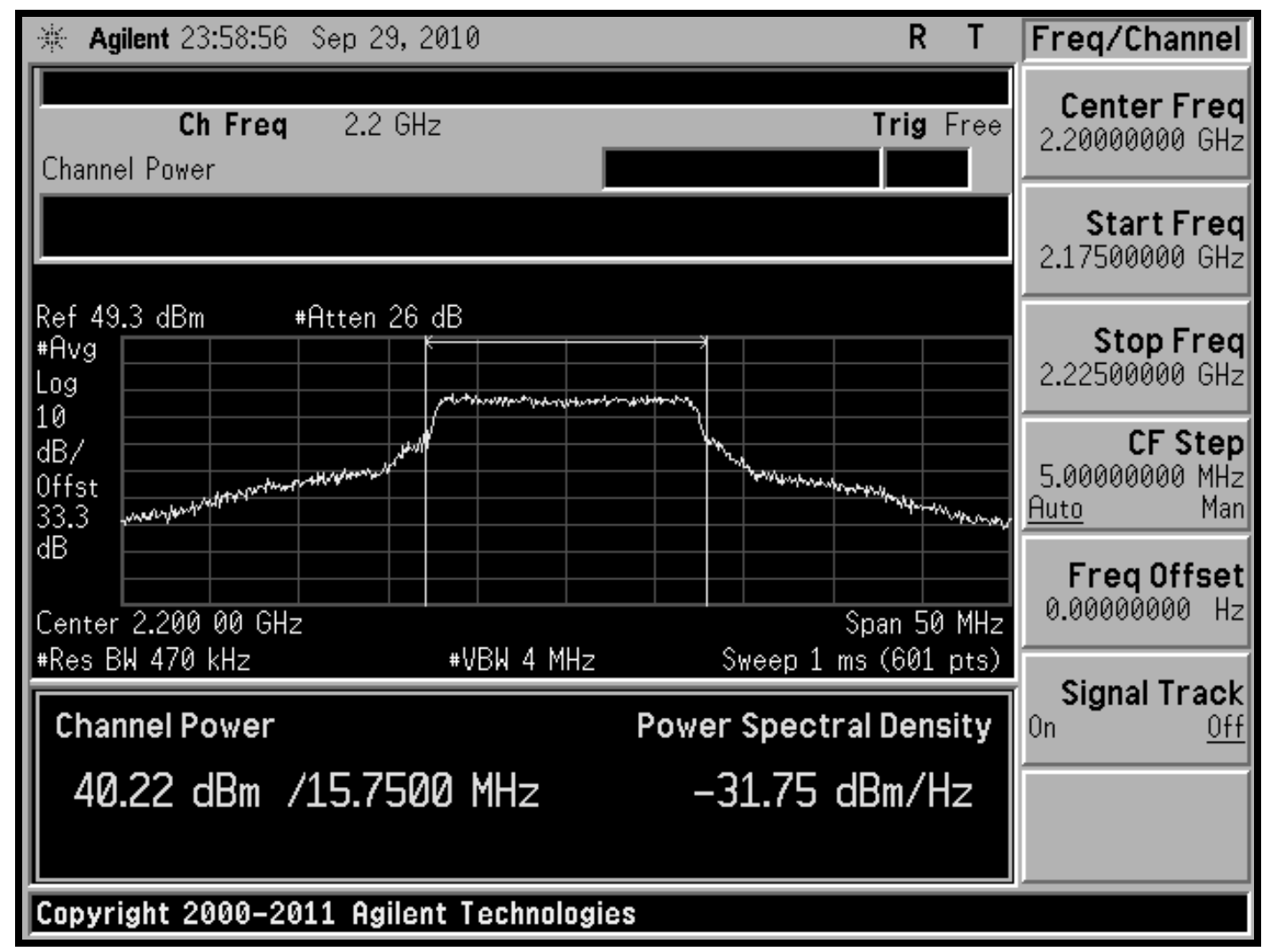

Figure 5.2 : Demonstration of Full Duplex streaming mode operation from Flight unit to test transceiver. LCOT Flight unit output power at transmit port is at $10 \mathrm{~W}$ 


\subsection{CONCLUSIONS}

The LCOT unit meets the technical challenge of LDPC codes, generation of OFDM modulation signal, and transmission of $10 \mathrm{~W}$ high PAPR signal inside a small and ruggedized enclosure. The LCOT module achieves a low cost solution by using off-the-shelf RF devices for the analog front and back ends and also incorporates a Field Programmable Gate Array (FPGA) as its main digital signal processing engine. The $10 \mathrm{~W}$ transmitted signal passes the IEEE $802.11 \mathrm{~g}$ spectral mask specifications.

\subsection{ACKNOWLEDGMENTS}

The authors would like to thank the SET team at Edwards Air Force Base for the use of their lab equipment and facilities during testing. 